\title{
Health Care Exclusion: An Examination in Bangladesh
}

\author{
Mr. Abu Taher Md. Sanaullah Nury', Mr. Amir Mohammad Sayem ${ }^{2}$ \\ ${ }^{1}$ Upazilla Family Planning Officer, Narayanganj Sadar, Narayanganj; ${ }^{2}$ Research Associate, Bangladesh Institute of Social Research, \\ Dhaka, Bangladesh.
}

\begin{abstract}
Bangladesh has made significant progress in many of its social development indicators particularly in health; however, a vast portion of its people still does not use health care services from medically trained providers. An attempt has been made in this study to investigate levels and patterns of health care exclusion among women in Bangladesh. A face to face crosssectional survey was carried out in a total of 674 married women, selected with the convenience sampling technique. This study was carried out in Bancharampur sub-district under Bramman Baria district and Mirpur sub-district under Dhaka district from 1st July to 30th July in 2010. Results revealed that the mean health care exclusion score was $14.0(\mathrm{SD}=4.40)$ out of 21 . The least used reason to explain health care exclusion was "A doctor recommended a surgery for a family member but we did not have it done", with only $9.9 \%$ of the subjects giving this reason. The most common reason was "A child in the family was sick but was unable to obtain the required health care" $(32.6 \%)$. Multivariate regression analysis found that the independent variables explained $37.8 \%$ of variance. Significant association of health care exclusion appeared with the participants' level of education $(B=-0.183, C I=-0.264$ to -0.102$)$, family's wealth status $(B=-0.803, C I=$ -0.970 to -0.637$)$, family size $(B=0.315, C I=0.214$ to 0.416 ), exposure to mass media $(B=0.415, C I=0.218$ to 0.612$)$ and history of ever use of health care service $(B=1.971, C I=1.238$ to 2.705$)$. It is suggested that women's education specific to health care utilization, health related mass media campaigns and effective counselling on positive aspects of health care by health professionals to the patients attending the clinics are necessary to reduce health care exclusion.
\end{abstract}

Keywords: Heath care, Exclusion, Examination, Differential patterns, Women, Bangladesh.

\section{Introduction}

At present, dramatic inequalities dictate global health, with the conditions in which people grow, live, work and age having a powerful influence on their health. ${ }^{1}$ It is particularly true in cities where half of the world's population currently lives and where the urban setting is a social determinant of health in itself. Interestingly, in the past two decades national governments, multilateral development agencies, and private voluntary organizations have focused on bolstering developing countries' institutional capacities to provide health care. ${ }^{3,4}$ Reducing social inequalities in health in general and the burden of ill health among the poor in particular are currently driving many global health research and activist agendas. The deep connections between poverty and health continue to be the source of intensive investigations in the twenty-first century, especially in low and middle-income countries where the burden of illness is the heaviest. ${ }^{5}$ In addition to ensuring that the poor have access to essential health services, there are attempts for poverty alleviation, as it has been considered to have positive effects on health.

Relatively, people living in poor economic environment do

\section{Practice points}

- Health care exclusion among women is higher in Bangladesh.

- Educated women and women with higher wealth status tend to be less excluded from health care.

- Women with larger family size tend to be more excluded from health care.

- Mass media exposure fails to influence women to utilize health care services effectively.

- Education and awareness, mass media campaigns and effective counselling are necessary to reduce health care exclusion.

not have access or have lower access to proper heath care services compared to people with better economic conditions. Economic differences create disparity in health care access in the world, especially in the developing countries. Consequently, differential access to health care leads to poor health outcomes; furthermore, populations lacking access to health services are at a greater risk for the

Correspondence: Mr. Amir Mohammad Sayem, Research Associate, Bangladesh Institute of Social Research, 6/14 (5th Floor), Lalmatia, Dhaka-1207, Bangladesh.Email: sayemphps@yahoo.com. 
adverse health consequences of both untreated chronic and acute diseases. In developing countries including Bangladesh, lack of access to health care is a major public health problem. More importantly, rising health care costs and a lack of social protection are also leading to financial burdens, especially among the poor ${ }^{6}$, who are vulnerable to exclusion from health care, indebtedness and impoverishment. Research indicates that higher fees and cost of transport associated with visiting medically qualified practitioners may result in a higher perception of costs and may act as a deterrent for seeking care from a qualified provider in Bangladesh. ${ }^{7}$

Evidence suggests that, in recent times, Bangladesh has made significant progress in many of its social development indicators particularly in health. ${ }^{8}$ All health indicators show steady gains and the health status of the population has improved including infant, maternal and under-five mortality rates have all decreased over the last decades, with a marked increase in life expectancy at birth. Evidence indicates that the availability and accessibility of modern effective medicines through the provision, by a well-trained and wellmanaged field personnel structure, have incremental impact on the utilization of modern health care. ${ }^{9}$ However, like most transitional societies, a wide range of therapeutic choices are available in Bangladesh, ranging from self care to traditional and western medicine. Although modern medical use is being increased, a vast portion of people still does not use health care services from medically trained providers or use health care services from traditional care providers.

\section{Access to/exclusion from health care}

Exclusion from health care has been considered lacking access to health care, i.e., people who have more access to health care have lower health care exclusion. The concept of "access" has been classified as potential access and realized access. ${ }^{10}$ Potential access indicates the probability that services will be obtained while realized access is the actual utilization of health care services. Potential access includes three categories of indicators such as predisposing, enabling, and need factors. ${ }^{11}$ Predisposing factors include demographic factors (age, gender), social structure (education, occupation), and health beliefs (attitudes, values, knowledge). Enabling resources are comprised of personal/ family (social relationships, income) and community resources (availability of health personnel and facilities, health insurance, a regular source of care) that are the means that individuals have for using health services. Need factors are based on how people view their own health and functional state; how individuals perceive symptoms of illness, pain, and worries about their health; and providerdiagnosed conditions.

Despite importance on better access to health care, fair access does not naturally imply equal health care utilization as access concerns mainly equality of probability or opportunity of using health services. Consequently, equal access criterion alone can not be adequate equity principle to follow. Evidence suggests that the threats of health care are greater for the elderly, who are more exposed to disease, particularly chronic morbidity, because it requires continual long-term care. ${ }^{12}$ With an aging population, chronic illness and disability play more prominent roles in women's lives, yet women's non-fatal health status is not well documented.$^{13}$ In addition, there is racial difference in health care. For example, African Americans and Hispanics have lower rates of access to a regular provider and to specialist care $^{14}$, which could be largely attributed to differences in the quality of health care facilities used by members of different races; i.e., those used by blacks provided fewer eye examinations in general. ${ }^{15}$

Upon the understanding of the abovementioned issues related to heath care inequality and hence differential access, an attempt has been made in this study to investigate health care exclusion in Bangladesh perspective. Specific objectives of this study were to investigate levels and differential patterns of health care exclusion among women of reproductive age group.

\section{Methods}

This study was conducted among 674 married women in Bangladesh, selected with convenience sampling technique. Participants were selected on the basis of two criteria such as women aged 15-49 years and women who were married during the survey in Bancharampur sub-district under Bramman Baria district and Mirpur sub-district under Dhaka district. A cross sectional survey was carried out with a semi-structured interview questionnaire. The interview questionnaire was developed in Bengali and pilot tested with six potential participants. Then the questionnaire was modified, including the insights of the pilot test and suggestions from experts, prior to applying it to participants. In total, six female interviewers were recruited to carry out the interview, three for each area. All the interviewers had 12-16 years of formal education with age ranging from 1822 years. They were trained on the content of the study and how to collect data. In addition, interviewers were instructed to take informed consent from each participant just before carrying out the interview. Participants were interviewed at their home. No other people were present except the participant and interviewer at the interview. Each interview lasted for around 25 minutes. Data collesction was carried out from $1^{\text {st }}$ July to $30^{\text {th }}$ July 2010.

\section{Measuring variables}

\section{Measuring health care exclusion}

The dependent variable, health care exclusion, was measured with a scale of 8 items. Exclusion to health care was measured at the household level. This is only a proxy of women's exclusion to care as gender-based barriers may affect women's access to and utilization of health care.$^{16}$ The responses included three points scale such as agree (1), neutral (2) and disagree (3); however, we reverted the 
direction at the analysis stage. Total score of health care exclusion was obtained by summing up individual score of each item, indicating that the higher the score the higher the health care exclusion. To test the internal consistency of the items, used in measuring health care exclusion, the Cronbach's alpha was calculated. Since it was much more $(0.8817)$ than generally used cut-off point $(0.70)$, the items were considered as strongly associated with each other and we used them as a single combined score of health care exclusion.

\section{Measuring independent variables}

Eight independent variables were used to find out the patterns of health care exclusion. These included participants' age at present (measured in completed years), year of schooling (measured in completed years), place of birth $(0=$ rural and $1=$ urban), exposure to mass media (measured in frequency of watching television, reading newspaper and listening radio per day), family size (total number of family members), distance between home and clinic (measured in $\mathrm{km}$ ), ever use of health care $(0=$ participants did not use health care ever and $1=$ participants used ever) and family economic status (measured in 9 household items such as radio/cassette player, active television, wall clock, motor cycle, bi-cycle, rickshaw/van, steel almirah, cot and mobile phone). Family economic status was measured by two responses $(0=$ no and $1=$ yes), where the total score was generated by summing up the individual score.

\section{Data Analysis}

Three types of statistical analyses were performed in order to address the study objectives. First, we used descriptive statistics to find out the levels of health care exclusion; in this regard, frequency and percentages were calculated for each of the items that examined health care exclusion (presented in Table 1). In addition, percentages of the independent variables were calculated. At the second stage, correlation coefficients were calculated using Pearson $\mathrm{R}$ statistics (presented in Table 2). At the final stage, multiple linear regression analyses were carried out to identify the patterns of health care exclusion. All the independent variables used at bi-variate analysis were used at multivariate analysis. Linear regression technique was used because the dependent and all the independent variables were at interval level except place of birth. To use it into linear technique, it was considered as a dichotomous variable. In addition, to diagnose multicollinearity among independent variables, we performed zero order correlation analysis. As correlation coefficient was 0.785 between husband's education and participants' education, husband's education was removed from our analysis. As no other correlation coefficients reached 0.70 or near to this level, all the independent variables were entered into regression analysis. Results of multivariate analysis are presented in the form of B, standard error, beta, t-value and confidence interval (presented in Table 3).

\section{Result \\ Background Characteristics}

Participants' had a mean age of 28.6 ( $\mathrm{SD}=8.17)$ years. More than one fourth of the participants $(27.0 \%)$ had no schooling, whereas $22.7 \%, 39.9 \%$ and $10.4 \%$ had respectively $1-5,6-10$ and $>10$ years of schooling. Participants mean wealth index was $5.91(\mathrm{SD}=1.53)$ out of 9

Table 1 Distribution of health care exclusion items

\begin{tabular}{|c|c|c|c|c|}
\hline & Health Care Exclusion Scale Items & $\begin{array}{l}\text { Disagree } \\
\mathrm{N}(\%)\end{array}$ & $\begin{array}{c}\text { Neutral } \\
\mathrm{N}(\%)\end{array}$ & $\begin{array}{l}\text { Agree } \\
\mathrm{N}(\%)\end{array}$ \\
\hline & $\begin{array}{l}\text { A child in the family was sick but was unable to obtain } \\
\text { the required health care }\end{array}$ & $151(22.4)$ & $303(45.0)$ & $220(32.6)$ \\
\hline & $\begin{array}{l}\text { An adult in the family was sick, but was unable to obtain } \\
\text { the required health care }\end{array}$ & $170(25.2)$ & $335(49.7)$ & $169(25.1)$ \\
\hline 3. & $\begin{array}{l}\text { An elderly member in the family was sick but was unable } \\
\text { to obtain the required health care }\end{array}$ & $187(27.7)$ & $390(57.9)$ & $97(14.4)$ \\
\hline & $\begin{array}{l}\text { A family member, having a chronic illness, had to stop } \\
\text { his/her treatment for a certain period of time }\end{array}$ & $375(55.6)$ & $157(23.3)$ & $142(21.1)$ \\
\hline 5. & $\begin{array}{l}\text { A doctor recommended a hospitalization for a family } \\
\text { member but we did not have it done }\end{array}$ & $324(48.1)$ & $163(24.2)$ & $187(27.7)$ \\
\hline 6. & $\begin{array}{l}\text { A doctor recommended a surgery for a family member } \\
\text { but we did not have it done }\end{array}$ & $429(63.6)$ & $178(26.4)$ & $67(9.9)$ \\
\hline 7. & $\begin{array}{l}\text { A doctor recommended a hospitalization for a family } \\
\text { member but we postponed }\end{array}$ & $265(54.2)$ & $178(26.4)$ & 131(19.4) \\
\hline
\end{tabular}

Mean $=14.0 ;$ Standard deviation $(\mathrm{SD})=4.40 ;$ Cronbach's alpha $=0.8817$ 
household items. Around one fifth (17.5\%), two fifth $(40.4 \%)$ and more than two fifth of the participants had respectively 1-3, 4-6 and 7-9 household items. On average, participants had 5 family members $(\mathrm{SD}=2.89)$ and had 2 hours $(\mathrm{SD}=1.53)$ of daily exposure to different mass media like radio, television and newspaper. The majority of the participants' birth place was rural (82.0\%). Women's ever use of health care service was low, i.e., $27.3 \%$ of participants. On average, the participants' home was around 2 kilometers away $(\mathrm{SD}=2.498)$ from the nearest clinic.

\section{Health care exclusion}

The mean health care exclusion score was $14.0(\mathrm{SD}=4.40)$ out of 21. The Cronbach's alpha for the items was 0.8817 , suggesting a strong inter-correlation among the items, and the items can be used as a single combined score in measuring health care exclusion. Health care exclusion was lowest $(9.9 \%)$ in "A doctor recommended a surgery for a family member but we did not have it done" while highest $(32.6 \%)$ in "A child in the family was sick but was unable to obtain the required health care". The details of health care exclusion are presented in Table 1.

Table 2 Zero-order correlations among dependent and independent variables

\begin{tabular}{|c|c|c|c|c|c|c|c|c|}
\hline $\begin{array}{l}\text { Participants' } \\
\text { characteristics }\end{array}$ & $\begin{array}{c}\text { Participants' } \\
\text { age }\end{array}$ & $\begin{array}{l}\text { Participants' } \\
\text { education }\end{array}$ & $\begin{array}{l}\text { Wealth } \\
\text { status }\end{array}$ & $\begin{array}{l}\text { Family } \\
\text { size }\end{array}$ & Birth place & $\begin{array}{l}\text { Exposure to } \\
\text { mass media }\end{array}$ & $\begin{array}{l}\text { Distance between } \\
\text { home \& clinic }\end{array}$ & $\begin{array}{l}\text { Ever use of } \\
\text { Health care }\end{array}$ \\
\hline $\begin{array}{l}\text { Participants } \\
\text { education }\end{array}$ & $-0.334 * * *$ & & & & & & & \\
\hline Wealth status & -0.004 & $-0.517 * * *$ & & & & & & \\
\hline Family size & $0.308 * * *$ & $-0.195 * * *$ & 0.048 & & & & & \\
\hline Birth place & $-0.083^{*}$ & $0.442 * * *$ & $-0.416^{* * *}$ & $0.138 * * *$ & & & & \\
\hline $\begin{array}{l}\text { Exposure to } \\
\text { mass media }\end{array}$ & $-0.088^{*}$ & $-0.354 * * *$ & $0.507 * * *$ & 0.039 & $0.240 * * *$ & & & \\
\hline $\begin{array}{l}\text { Distance } \\
\text { between home } \\
\text { \& clinic }\end{array}$ & $0.090 *$ & $0.081 *$ & -0.069 & $0.152 * * *$ & $-0.099 *$ & -0.062 & & \\
\hline $\begin{array}{l}\text { Ever use of } \\
\text { health care }\end{array}$ & $0.274 * * *$ & $0.158 * * *$ & $0.110^{* *}$ & -0.048 & 0.026 & $0.147^{* * *}$ & 0.056 & \\
\hline Health care & $0.186 * * *$ & $0.485 * * *$ & $-0.527 * * *$ & $0.286 * * *$ & $-0.357 * * *$ & $-0.247 * * *$ & $0.101 *$ & $0.108 * *$ \\
\hline
\end{tabular}

$* * * \mathrm{p}<0.001 ; * * \mathrm{p}<0.01 ; * \mathrm{p}<0.05$

Table 3 Multi- variate regression analysis of health care exclusion

\begin{tabular}{|lllllll|}
\hline Participants' characteristics & B & Std. Error & Beta & t-value & \multicolumn{2}{c|}{$95 \%$ CI } \\
(Constant) & $14.480^{* * *}$ & 0.811 & & 17.844 & 12.886 & 16.073 \\
Participants' age & 0.033 & 0.020 & 0.059 & 1.673 & -0.006 & 0.073 \\
Participants' education & $-.0183^{* * *}$ & 0.041 & -0.186 & -4.438 & -0.264 & -0.102 \\
Wealth status & $-0.803^{* * *}$ & 0.085 & -0.411 & -9.480 & -0.970 & -0.637 \\
Family size & $0.315^{* * *}$ & 0.051 & 0.211 & 6.117 & 0.214 & 0.416 \\
Birth place & -0.711 & 0.387 & -0.069 & -1.838 & -1.470 & 0.049 \\
Exposure to mass media & $0.415^{* * *}$ & 0.100 & 0.151 & 4.134 & 0.218 & 0.612 \\
Distance between home \& clinic & 0.020 & 0.055 & 0.012 & 0.364 & -0.088 & 0.128 \\
Ever use of health care & $1.971^{* * *}$ & 0.374 & 0.179 & 5.277 & 1.238 & 2.705 \\
$\mathrm{R}^{2}$ & 387 & & & & & \\
Adjusted $\mathrm{R}^{2}$ & 378 & & & & & \\
\hline
\end{tabular}

$* * * \mathrm{p}<0.001$ 


\section{Associations of health care exclusion}

Result revealed that participants with higher age had higher tendency to exclude health care services $(r=0.186, \mathrm{p}<0.001)$ (Table 2). Similarly, family and distance between home and clinic had significant positive correlation with health care exclusion. Conversely, participants' education $(r=-0.485$, $\mathrm{p}<0.001)$, family wealth status $(r=-0.527, \mathrm{p}<0.001)$, mass media exposure $(r=-0.247, \mathrm{p}<0.001)$ and ever use of health care $(r=-0.101, \mathrm{p}<0.01)$ were negatively correlated with health care exclusion. In addition, participants whose birth place were urban area had lower tendency to exclude health care $(r=-0.357, \mathrm{p}<0.001)$ compared to that of rural area.

The multivariate regression analysis revealed that the independent variables explained $37.8 \%$ of variance in health care exclusion (Table 3). Participants' education had significant negative impact on health care exclusion $(\mathrm{B}=-$ $0.183, \mathrm{CI}=-0.264$ to -0.102 ). In addition, family wealth status $(\mathrm{B}=-0.803, \mathrm{CI}=-0.970$ to -0.637$)$ had negative impact on health care exclusion. Conversely, family size $(B=0.315$, $\mathrm{CI}=0.214$ to 0.416$)$, exposure to mass media $(\mathrm{B}=0.415$, $\mathrm{CI}=0.218$ to 0.612 ) and ever use of health care service $(B=1.971, C I=1.238$ to 2.705$)$ had significant positive impact on health care exclusion. Individually, both exposure to mass media and women's ever use of health care services were negatively correlated with health care exclusion at bi-variate analysis; however, unexpectedly these were positively associated when multi-variate analysis was performed. Perhaps, in multivariate settings, interaction with other variables caused these two variables appeared to be positive with health care exclusion.

\section{Discussion}

Much of the studies focused on health care utilization, especially maternal health care utilization in Bangladesh ${ }^{17,18}$ and elsewhere ${ }^{19-23}$ - but there is a paucity of studies regarding health care exclusion ${ }^{16}$. Till the date, no study has been carried out in Bangladesh to investigate health care exclusion. Although health care utilization is the opposite of health care exclusion, the later has important bearing in that it gives opportunity to identify the people who are excluded from health care utilization and why they are excluded, making intervention easier. However, due to lack of studies on it, measurement of health care exclusion was an important challenge.

This study was an attempt to fill the gap and find out levels and patterns of exclusion from heath care. This study found that health care exclusion was more than moderate for married women, i.e., women scored 14 out of 21 , suggesting a higher level of health care exclusion. Health care exclusion is reportedly higher in the current study compared to another study conducted in India ${ }^{16}$, which found around one third participants with health care exclusion; perhaps, measurement might have an important reason behind such difference, since exclusion was defined in the current study as summed up measures of all items while in the previous study as at least one situation of exclusion over the past 12 months. ${ }^{16}$ Differences may also come from differences between the areas of study, as India is more economically advanced country compared to Bangladesh.

In our study, the highest exclusion appeared with "A child in the family was sick but was unable to obtain the required health care", suggesting lower level of child care utilization. Generally, health care utilization for children is low in our country; more importantly, women's decision making authority regarding health care for children is $\operatorname{lower}^{24}$, suggesting women's inaccessibility, which may be partly responsible for lower health care utilization for children along with limited resources with higher necessary expenditure on other family matters rather than child health care. On the other hand, the lowest exclusion was in "A doctor recommended a surgery for a family member but we did not have it done", suggesting doctors' recommendations are highly appreciated in Bangladesh. It is expected in our culture where people usually visit doctor in critical health situation that warrants immediate treatment for the betterment of patients; in this case, people obey doctors' suggestions as a last resort for survival.

This study revealed that women's education lowers the chance of health exclusion, which is similar to another study in that there was positive association between health care utilization and women education. ${ }^{18}$ Education's negative impact on health care exclusion is expected as educated women are more aware about health and can better manage family members to pursue health care utilization and are less likely to be excluded from health care. Similarly, wealth status appeared to have negative impact on health care exclusion. In general, household income is correspondingly associated with health status and the purchasing power of goods and services, especially health care services. ${ }^{25,26}$

Health exclusion was higher among those exposed to mass media, which is contrary to another study ${ }^{18}$, where mass media exposure had positively associated with utilization of maternal health care services. Evidence suggests that mass media increases awareness about innovations, and fosters inter-personnel communication, which could facilitate behavioral changes allowing for the adoption of new/different behaviors. ${ }^{27}$ Contrary finding in the current study might be because of several reasons like women's poor family status suggesting financial incapacity and watching entertainment program rather than health related program suggesting no impact of mass media.

In the current study, family size had positive impact on health care exclusion. It is expected that larger family size has health related budget constraint because of other family needs such as cost of rearing children and cost of education. With the limited family income in most of families in the developing countries like Bangladesh, it is often not possible to use health care. Reducing family size through reducing fertility may be an important issue to consider in 
reducing health care exclusion while increasing health care utilization. Furthermore, we found that women who ever used health care services had higher tendency to be excluded from health care. Women's exposure to health care use might have generated negative attitude towards health care providers and perception of higher costs of treatment.

Despite pioneer initiative in investigating health care exclusion in Bangladesh, findings of the current study should be considered with limitations. First measurement of health care exclusion was based on only eight items without any reliability test in the previous study. ${ }^{16}$ Future study may be conducted with more items that represent a holistic perspective of health care exclusion. Second, although this study measured health care exclusion at household level, we collected data from women only. Data from both male and female participants would better represent the sample population and findings. We recommend for inclusion of male participants in future studies conducting on health care exclusion. Finally, our regression model explained about $38 \%$ variance in health care exclusion, which is relatively weak model, suggesting that there are other variables that explain it well. We suggest to incorporate a broader socioeconomic and cultural aspect in future studies so that independent variables explain dependent variable well.

\section{Conclusion and implications}

An attempt has been made in this study to investigate health care exclusion among women at household level in Bangladesh and found a high level of exclusion from health care. Several independent variables, contributed to the health care exclusion, such as participants' education, wealth status, family size, mass media exposure and ever use of health care services by women. Based on the findings of the current study, the followings are being suggested:

First, women's education, as appeared to have negative impact on health care exclusion, may be an important tool to reduce health care exclusion. However, general education may not generate optimum outcome in this regard, rather specific education related to utilization of health care service may be more important and effective. In this regard, future case-control study (mass media exposure to health education and no exposure to health education) may provide an important guideline to include health education in mass media awareness programs. Second, women should be exposed to mass media with programs related to health care utilization rather than only entertaining programs. More health related programs are needed to disseminate through mass media including television and radio. Further studies may be required to understand the content of effective mass media exposure to heath care utilization. Finally, women's ever use of health care services appeared to have higher health care exclusion. Perhaps family members of women usually receive health care at the very critical situation of illness/disease and women had negative perception about service provider. In this regard, we suggest that in order to reduce health care especially those women who ever received health care, it is necessary to provide counseling on the positive aspects of health care and necessity for visiting a doctor immediately once women perceive any kind of disease or illness, especially to the patients come to the clinic.

\section{References}

1. World Health Organization. Achieving health equity: from root causes to fair outcomes. Geneva: World Health Organization, 2007.

2. Mercado S, Havemann K, Sami M, Ueda H. Urban poverty: An urgent public health issue. J Urban Health 2007; 3: 7-15.

3. Grant J. UNICEF and the health of mothers and children. In: Wallace HM, Giri K, editors. Health care of women and children in developing countries. Oakland: Third Party Publishing, 1990.

4. Jamison D, Mosley W. Disease control priorities in developing countries: health policy responses to epidemiologic change. Am J Pub Health 1991; 81: 15-22.

5. Wagstaff A. Poverty and health. CMH Working Paper Series, WG1 5. Geneva: World Health Organization, 2001.

6. Levesque JF, Haddad S, Narayana D, Fournier P. Uneven options for accessing health care in developing world cities: a multilevel analysis of outpatient care utilisation in urban Kerala, India. Health Pol Plan 2006; 21:289-301.

7. Wahed T, Mahmood SS, Bhuiya A. Costs associated with use of healthcare services in Chakaria, Bangladesh. http://www.icddrb.org/publication.com classificationID=0\&pubID=9995. (accessed Feb 2011)

8. World Health Organization. Health system in Bangladesh. WHO, Bangladesh, 2011. http://www.whoban.org/health_system bangladesh.ht ml. (accessed Feb 2011)

9. Amin R, Chowdhury SA, Kamal GM, Chowdhury J. Community health services and health care utilization in rural Bangladesh. Soc Sci Med 1989; 29: 1343-9.

10. Aday LA, Andersen R. Development of indices of access to medical care. Ann Arbor: Health Administration Press, The University of Michigan; 1975.

11. Andersen R, Aday LA. Access to medical care in the U.S.: realized and potential. Med Care 1978; 16: 533-46.

12. Kart CS. Human aging and chronic disease. Boston: Jones and Bartlett, 1992.

13. Mohindra KS, Haddad S, Narayana D. Women's health in a rural community in Kerala, India: do caste and socioeconomic position matter? J Epidem Commun Health 2006; 60: 1020-6. 
14. Heisler M, Smith DM, Hayward RA, Krein SL, Kerr EA. Racial disparities in diabetes care processes, outcomes, and treatment intensity. Med Care 2003; 41: 1221-32.

15. Gornick ME, Eggers PW, Reilly TW et al. Effects of race and income on mortality and use of services among Medicare beneficiaries. NEJM 1996; 335: 791-9.
16. Mohindra KS, Haddad S, Narayana D. Can microcredit help improve the health of poor women? Some findings from a cross-sectional study in Kerala, India. Int $J$ Equity Health 2008; 7: 1-14. 